\title{
Infanticide or interference: Does the great reed warbler selectively destroy eggs?
}

\author{
Alfréd Trnka ${ }^{1, *}$, Pavol Prokop ${ }^{1,2} \&$ Péter Batáry ${ }^{3}$ \\ 1) Department of Biology, University of Trnava, Priemyselná 4, SK-918 43 Trnava, Slovakia \\ (corresponding author's e-mail: atrnka@truni.sk) \\ 2) Institute of Zoology, Slovak Academy of Sciences, Dúbravská cesta 9, SK-845 06 Bratislava, \\ Slovakia \\ 3) Agroecology, Georg-August University, Waldweg 26, D-37073 Göttingen, Germany
}

Received 8 June 2009, revised version received 30 Sep. 2009, accepted 18 Sep. 2009

Trnka, A., Prokop, P. \& Batáry, P. 2010: Infanticide or interference: Does the great reed warbler selectively destroy eggs? - Ann. Zool. Fennici 47: 272-277.

Infanticide, the killing of offspring by adult conspecifics, has been demonstrated in many insect, mammal and bird species. In contrast to selective pressures influencing infanticide in other species, egg destruction in birds is thought to primarily represent interference competition for food, nest sites or predator-free nesting space. In the case of the great reed warbler, two opposing hypotheses exist for the explanation of its egg destruction behaviour. Our study tested these hypotheses separately by manipulating the presence of real conspecific, familiar and unfamiliar eggs and nests inside polygynous and monogamous great reed warbler territories. Out of 147 experimental nests placed in the vicinity of 49 active great reed warbler nests, only conspecific eggs were preyed upon by great reed warblers. Furthermore, significantly more great reed warbler nests were destroyed in polygynous than monogamous territories. These results support the hypothesis that egg destruction behaviour in this species is motivated intraspecifically and most probably intrasexually.

\section{Introduction}

Infanticide refers to the killing of young or destruction of eggs by members of the same species. It is an adaptive trait that provides potential benefits to the perpetrator (van Schaik \& Janson 2000). Both natural and sexual selection pressures contributed to the evolution of this behaviour (Hrdy 1979, Ebensperger 1998). The former factor involves mainly nutritional gains, increased access to limited resources or avoidance of parental investment in unrelated young, the latter factor the gain new sexual partner. While male infanticide represents a sexual strategy (Crook \& Shields 1985, Møller 1988), the most common causes of female infanticide are competition for breeding resources or infant exploitation (cannibalism). Sexually selected infanticide by females has been reported only in bird species (Veiga 1990, 2004), among them the great reed warbler, a small polygynous passerine that breeds in reed beds of marshes and lakes throughout temperate Europe and westernmost Asia (Cramp 1992). Secondary females inhabiting the territory of a primary female of this species are known to destroy the eggs of primary females in order to gain increased paternal investment (Bensch \& Hasselquist 1994, Hans- 
son et al. 1997). Great reed warblers, however, are also suspected of destroying eggs of other bird species, probably as a form of interference competition. This behaviour has also been described in other small passerines (Bowman \& Carter 1971, Creighton \& Porter 1974, Picman 1977, Belles-Isles \& Picman 1986, Weisheit \& Creighton 1989, Simons \& Simons 1990).

Destruction of nests or eggs of other bird species by the great reed warbler was described for the first time by Hoi et al. (1991). They observed great reed warblers destroying the nests of reed warbler Acrocephalus scirpaceus and moustached warbler Acrocephalus melanopogon. This was supported by Honza et al. (1999), who suggested that this behaviour is common among great reed warblers. Finally, Batáry et al. (2004) reported high intra- and interspecific nest predation by great reed warblers as well as reed warblers in their artificial nest study. Since direct observations of great reed warblers destroying the eggs of their own or other species are scarce, these patterns have been studied predominantly in experiments with artificial nests (Hansson et al. 1997, Honza et al. 1999, Batáry et al. 2004). In most of these studies, however, the experiments were performed in areas where great reed warblers bred sympatrically with reed warblers or other potential egg destroyers. Moreover, artificial nests were baited with only one type of dummy eggs.

From existing findings it is not clear if the dummy eggs in previous experiments were destroyed exclusively by great reed warblers, and if so, whether the nest predation events were a result of intrasexual, or intra- or interspecific interference competition. To address these questions we performed an experiment with three types of manipulated real eggs, in localities without potential great reed warbler competitors. First, we manipulated the presence of conspecific (great reed warbler), familiar (reed warbler) and unfamiliar (red-backed shrike Lanius collurio) real eggs inside great reed warbler territories to test whether egg destruction (measured by small peck marks on the eggs) is selective for great reed warbler eggs and thus intraspecifically motivated, or unselective and interspecifically motivated. Second, we manipulated the presence of great reed warbler nests with real eggs inside polygynous and monogamous great reed warbler territories. If egg destruction is a result of intrasexual competition between great reed warbler females to gain a higher proportion of male parental investment (Hansson et al. 1997), then great reed warblers should destroy conspecific eggs more frequently in polygynous than in monogamous territories. Finally, we compared selected breeding parameters and individual quality of great reed warblers in relation to conspecific egg predation to test whether there is some mechanistic explanation for when females are more likely to destroy the eggs of their own species.

\section{Material and methods}

The study was carried out during the breeding period in 2007 at seven small ponds and gravel pits in vicinity of Trnava, southwestern Slovakia. The study localities ranged from two to five hectares and were surrounded by narrow belts of reed beds (maximum width 2-4 m). There was a total absence of trees or higher shrubs along the shore of the gravel pits, however some scattered willows were located around the ponds. This landscape configuration may explain the low level of cuckoo parasitism (see Results) in the great reed warbler study population (Moskát \& Honza 2000). Despite poor littoral vegetation, great reed warblers are relatively abundant in these ponds: in 2007 we determined 49 territories with 76 active nests (28 monogamous territories with 28 monogamous nests, 21 polygynous territories with 21 primary female's nests, 21 secondary female's nests and two tertiary female's nests and four rest nests were replacement for preyed upon or abandoned first nests). The average level of polygyny reached about 43\%. Other breeding bird species in the study areas included little grebe Tachybaptus ruficollis, little bittern Ixobrychus minutus and coot Fulica atra.

At the start of the study period in early May 2007, we located and mist netted all singing males occurring in the study areas. We used tape recordings of conspecific song (tape lures) to attract them to $12-\mathrm{m}$-long nets opened in their vicinity. Females were mist-netted at or near 
the nests at the end of the experiment so as not to disturb breeding initiation. All captured birds we marked with both aluminium and colour rings, measured and weighed. The physical condition of each bird we determined as residuals of regression of the weight and wing length (Senar et al. 1992, Yong \& Moore 1997). We recorded social activities and locations of colour-ringed males and outlined their territories on maps of the study areas. Simultaneous to the above procedures, we systematically searched the reed beds at 4-5 day intervals to locate the nests. This resulted the detection of most of the great reed warbler nests during the nest building or egg laying periods. The social status of each male (monogamy or polygyny) and status of each found nest and female (monogamous, primary, secondary) we determined subsequently on the basis of direct observations of ringed males and females repeatedly defending their territory and nests.

The experiment was performed between 15 May and 15 June 2007. In each trial, we placed three artificial nests at three meter distance from the active monogamous and primary female's nest of the great reed warbler (a total of 84 artificial nests in monogamous territories and 63 nests in polygynous territories). All great reed warbler natural nests were at an early stage (i.e. during egg laying). We used abandoned great reed warbler nests as experimental nests baited with four manipulated real eggs of the great reed warbler, reed warbler or red-backed shrike obtained from failed nesting attempts (flooded, preyed upon or deserted nests, infertile eggs) during previous nest studies. The nests were attached with a green fine wire to the reed stems at a height of $1 \mathrm{~m}$. The manipulated eggs had their contents replaced with liquid plasticine and then were attached to the nest with a nylon string. In the event of predation, peck marks left behind in the hardened plasticine allowed the predator to be identified. The artificial nests were checked every third day. Experiments were terminated if any eggs showed small marks indicating intraspecific predation, or if eggs were still intact after eight days. This period corresponds to the time when secondary females settle in the territory after the primary females' settlement (in case of polygynous males) and when we would expect predation of artificial nests caused by infanticide (see also Bensch \& Hasselquist 1994). To avoid habituation or other methodological errors, we performed the experiment only once in each great reed warbler territory. Eggs with peck marks were examined at 10-40× magnification under a stereo microscope. Predators were identified on the basis of the peck marks in accordance with Hansson et al. (1997). Because of absence of other reed passerines, we compared the peck marks only with marks of the great reed warbler, little bittern and common cuckoo Cuculus canorus which nested in study localities, and with marsh harrier Circus aeruginosus that occasionally was observed flying over the ponds.

Since there are known positive correlations between nest concealment, nest location and nest survival (Ille et al. 1996, Honza et al. 1998, Hansson et al. 2000, Batáry et al. 2004), at the end of the experiment for each artificial nest we measured the following nest characteristics: distance from the nest to the open water-reed edge, number of all reed stems within one square of $0.5 \times 0.5 \mathrm{~m}$ with the nest in the center, height and diameter of ten randomly chosen stems in each square and distance from the territory to the nearest territory of another male.

We used both parametric (ANOVA) and nonparametric tests (Chi-square) for the data analysis. We compared differences in nest characteristics between artificial nests with eggs of the great reed warbler, reed warbler and red-backed shrike placed in monogamous and polygynous territories using a nested ANOVA in which type of eggs was nested in the type of territory. All statistical tests were two-tailed and performed using Statistica software (StatSoft 2001).

\section{Results}

\section{Nest site characteristics of artificial nests}

Distances to the open-water reed edge, densities, heights and thicknesses of stems did not differ significantly between the three types of artificial nests (nested ANOVA: $F_{4,141}=0.45,0.38,0.48$ and 1.99, all $p$ 's $>0.10$, respectively, $n=147$ ). Nests placed in monogamous and polygynous 
territories did not differ with respect to the distance to the open-water reed edge and density $\left(F_{1.141}=0.72\right.$ and $3.13, p=0.77$ and $0.08, n=84$ and 63 , respectively). Monogamous territories of great reed warblers tended to be placed in taller and thicker vegetation $\left(F_{1,141}=13.52\right.$ and 12.14 , both $p<0.01$, respectively, $n=28)$. Nests with great reed warbler eggs placed in monogamous territories were located in thicker reeds than nests with the other two egg types (Tukey's post-hoc comparison, $p<0.01, n=28$ ). Tukey post hoc test on height of stems did not yield any significant differences between groups.

Similarly, there were no differences in height and thickness of stems (Mann-Whitney $U$-test: $U=22.0$ and $40.0, p=0.07$ and 0.74 , respectively) or distance to the open-water reed edge ( $U=31.5, p=0.30)$ between nests preyed upon by great reed warblers and intact nests $(n=$ 8 and 11, two nests disappeared, respectively) located in polygynous territories. However, nests destroyed by great reed warblers were situated in more dense vegetation than undamaged nests ( $U$ $=17.0, p=0.03, n=8$ and 11, respectively).

\section{Nest predation}

We used 28 monogamous and 21 polygynous territories, in each case using the first nest of a great reed warbler female. Two of 49 natural nests were successfully parasitised by common cuckoo, and five were preyed upon by an unknown predator. All nest contents or whole nests of above mentioned five nests were destroyed or disappeared. Altogether, 27 (18.4\%) of the 147 artificial nests were preyed upon.
From these, ten nests with great reed warbler eggs were destroyed almost certainly by great reed warblers, two nests by marsh harriers and one nest by little bitterns (Table 1). Nests with reed warbler eggs were preyed upon by marsh harriers (two nests), little bitterns (one nest) and unknown mammals (four nests), and nests with red-backed shrike eggs by marsh harriers (three nests), little bitterns (three nest) and unknown mammal (one nest). Peck marks closely resembling those made by the bill of the great reed warbler were distributed exclusively on conspecific eggs. It is evident that significantly more nests were destroyed in polygynous than monogamous territories (Fisher's exact test: $p=0.012$, $n=8$ and 2, respectively) (Fig. 1). In the case of polygynous territories, the settlement of secondary females was always confirmed.

\section{Body condition and clutch size}

We measured and weighed 67 females and 49 males of the great reed warbler. Because infanticide was carried out almost exclusively by secondary females, we used data from polygynous territories only, i.e. from 21 primary and 21 secondary females that had been settled in the territories at the time of experimental field work. However, there were no differences in physical condition between females suspected of destroying conspecific eggs and other females (mean \pm $\mathrm{SE}$ residual values $=0.11 \pm 0.94, n=8$ and -0.33 $\pm 0.45, n=34$, respectively, Mann-Whitney $U$-test: $U=129.0, p=0.82)$. Similarly, physical condition of polygynous males in whose territories egg destruction was detected did not differ

Table 1. Nest predators identified from peck marks left on three types of eggs placed in old great reed warbler nests located in monogamous and polygynous great reed warbler territories (GRW = great reed warbler, RW = reed warbler, RBS = red-backed shrike).

\begin{tabular}{|c|c|c|c|c|c|c|c|c|}
\hline \multirow[t]{2}{*}{ Type of predator } & \multicolumn{4}{|c|}{ Monogamous male territories } & \multicolumn{4}{|c|}{ Polygynous male territories } \\
\hline & GRW & RW & RBS & $\begin{array}{c}\text { Total } \\
(n=84)\end{array}$ & GRW & RW & RBS & $\begin{array}{c}\text { Total } \\
(n=63)\end{array}$ \\
\hline Marsh harrier & 2 & 1 & 2 & 5 & & 1 & 1 & 2 \\
\hline Little bittern & & 1 & 2 & 3 & 1 & & 1 & 2 \\
\hline Great reed warbler & 2 & & & 2 & 8 & & & 8 \\
\hline Mammal & & 2 & 1 & 3 & & 2 & & 2 \\
\hline Total & 4 & 4 & 5 & 13 & 9 & 3 & 2 & 14 \\
\hline
\end{tabular}




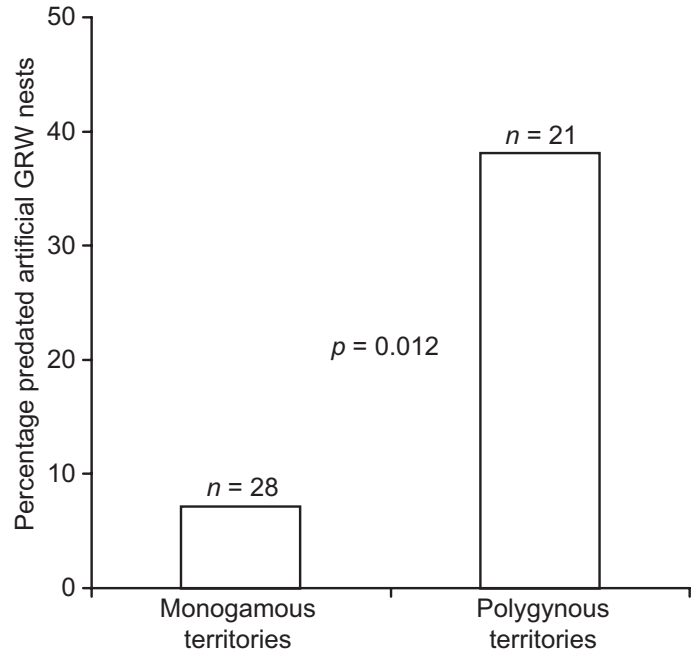

Fig 1. Percentages of destroyed artificial great reed warbler (GRW) nests by conspecifics in monogamous and polygynous male territories (compared with Fisher exact test).

from that of the other males (mean \pm SE residual values $=0.32 \pm 0.49, n=8$ and $-0.19 \pm 0.38, n=$ 13 , respectively, $U=37.0, p=0.28$ ).

There were also no differences in the clutch size between egg predatory and non-egg predatory great reed warbler females nesting in polygynous territories (mean $\pm \mathrm{SE}=3.62 \pm 0.54, n=8$ and $3.50 \pm 0.26, n=34$, respectively, $U=129.0$, $p=0.84)$.

\section{Discussion}

In our study areas, $37 \%$ of all nests that were preyed upon showed signs of great reed warbler predation. Because there were no other passerine birds present in the study localities, we can assume that small peck marks left on the experimental eggs were made exclusively by great reed warblers. Thus, these results provide further strong evidence that egg destruction behaviour is frequent if not common among great reed warblers, as has been also suggested by Hansson et al. (1997) and Honza et al. (1999).

Two explanations have been proposed for this behaviour to date. First, great reed warblers destroy the nests and eggs of other birds in order to reduce interspecific competition (Hoi et al. 1991, Honza et al. 1999). Our results, however, reject this hypothesis. Since great reed warblers are known to differentiate between their own and other eggs (Lotem et al. 1995, Moskát \& Hauber 2007) according to reflectance from ultraviolet and other spectras (see also Bennett \& Cuthill 1994, Honza et al. 2007, Cherry et al. 2007), we used manipulated real eggs of their own, familiar and unfamiliar species. In spite of this, none of the experimental reed warbler and red-backed shrike eggs showed signs of great reed warbler predation in our study area. This strongly suggests that egg destruction behaviour in great reed warblers is strictly motivated intraspecifically.

These findings support the second hypothesis that egg destruction is caused by infanticidal great reed warbler females competing for polygynous males. Strong indirect evidence of this was provided by Hansson et al. (1997). They showed in their experiment with dummy eggs that infanticide (measured by small peck marks resembling those of the great reed warbler) occurred almost exclusively when a new great reed warbler female settled in an already occupied territory. In our experiment we created a similar situation in which, however, a settling 'secondary' female would find herself in a territory with three types of nests (conspecific, familiar and unfamiliar). The results showed again that only great reed warbler eggs were preyed upon by great reed warblers and, more importantly, that significantly more great reed warbler nests were destroyed in polygynous than in monogamous territories. Thus, our results are more consistent with the Hansson et al. (1997) hypothesis that secondary females of the great reed warbler destroy the eggs of primary females to gain increased paternal investment. Furthermore, there were no differences found in selected physical and breeding parameters between egg predators and other birds that would provide other (mechanistic) reasons for this behaviour.

This begs the question: if egg destruction by great reed warblers is selective for eggs of their own species, what was responsible for the destruction of non-mimetic artificial eggs in previous experiments? We suspect the reed warbler of this crime. One motive for reed warblers to destroy a variety of nests could be that this would decrease nesting density and ultimately predation pressure in their own territory. How- 
ever, more observations and additional experimental studies are needed to test this hypothesis further.

\section{Acknowledgements}

We thank Staffan Bensch, Leena Lindström and Csaba Moskát for valuable comments on earlier version of the manuscript, Francisco Valera for some statistical comments, and L. Sutcliffe for linguistic revision. The experiments were conducted in compliance with the law of Slovakia. Péter Batáry was supported by the Alexander von Humboldt Foundation. This work was supported by the Slovak Grant Agency for Science VEGA, project no. 1/3257/06.

\section{References}

Batáry, P., Winkler, H. \& Báldi, A. 2004: Experiments with artificial nests on predation in reed habitats. - Journal of Ornithology 145: 59-63.

Belles-Isles, J. C. \& Picman, J. 1986: House wren nestdestroying behavior. - Condor 88: 190-193.

Bennett, A. T. D. \& Cuthill, I. C. 1994: Ultraviolet vision in birds - what is its function. - Vision Research 34: 1471-1478.

Bensch, S. \& Hasselquist, D. 1994: Higher rate of nest loss among primary than secondary females: Infanticide in the great reed warbler? - Behavioral Ecology and Sociobiology 35: 309-317.

Bowman, R. I. \& Carter, A. 1971: Egg-pecking behavior in Galapagos mockingbirds. - Living Bird 10: 243-270.

Cherry, M. I., Bennett, A. T. D. \& Moskát, C. 2007: Host intra-clutch variation, cuckoo egg matching and egg rejection by great reed warblers. - Naturwissenschaften 94: 441-447.

Cramp, S. (ed.) 1992: Handbook of the birds of Europe, the Middle East and North Africa VI. - Oxford University Press, New York.

Creighton, P. D. \& Porter, D. K. 1974: Nest predation and interference by western meadowlarks. - Auk 91: 177-178.

Crook, J. R. \& Shields, W. M. 1985: Sexually selected infanticide by adult male barn swallows. - Animal Behaviour 33: 754-761.

Ebensperger, L. A. 1998: Strategies and counterstrategies to infanticide in mammals. - Biological Reviews 73: 321-346.

Hansson, B., Bensch, S. \& Hasselquist, D. 1997: Infanticide in great reed warblers: secondary females destroy eggs of primary females. - Animal Behaviour 54: 297-304.

Hansson, B., Bensch, S. \& Hasselquist, D. 2000: Patterns of nest predation contribute to polygyny in the great reed warbler. - Ecology 81: 319-328.

Hoi, H., Eichler, T. \& Dittami, J. 1991: Territorial spacing and interspecific competition in three species of reed warblers. - Oecologia 87: 443-448.
Honza, M., Øien, I. J., Moksnes, A. \& Roskaft, E. 1998: Survival of reed warbler Acrocephalus scirpaceus clutches in relation to nest position. - Bird Study 45: 104-108.

Honza, M., Moksnes, A., Roskaft, E. \& Øien, I. J. 1999: Effect of great reed warbler Acrocephalus arundinaceus on the reproductive tactics of the reed warbler A. scirpaceus. - Ibis 141: 489-506.

Honza, M., Polačiková, L. \& Procházka, P. 2007: Ultraviolet and green parts of the colour spectrum affect egg rejection in the song trush (Turdus philomelos). - Biological Journal of the Linnean Society 92: 269-276.

Hrdy, S. H. 1979: Infanticide among animals: a review, classification, and examination of the implications for the reproductive strategies of females. - Ethology and Sociobiology 1: 13-40.

Ille, R., Hoi, H. \& Kleindorfer, S. 1996: Brood predation habitat characteristics and nesting decisions in Acrocephalus scirpaceus and A. palustris. - Biologia 51: 219-225.

Lotem, A., Nakamura, H. \& Zahavi, A. 1995: Constrains in egg discrimination and cuckoo-host coevolution. Animal Behaviour 49: 1185-1209.

Moskát, C. \& Honza, M. 2000: Effect of nest and nest site characteristics on the risk of cuckoo Cuculus canorus parasitism in the great reed warbler Acrocephalus arundinaceus. - Ecography 23: 335-341.

Moskát, C. \& Hauber, M. E. 2007: Conflict between egg recognition and egg rejection decisions in common cuckoo (Cuculus canorus) hosts. - Animal Cognition 10: 377-386.

Møller, A. B. 1988: Infanticidal and anti-infanticidal strategies in the swallow Hirundo rustica. - Behavioral Ecology and Sociobiology 22: 365-371.

Picman, J. 1977: Destruction of eggs by the long billed marsh wren (Telmatodytes palustris palustris). - Canadian Journal of Zoology 55: 1914-1920.

Senar, J. C., Burton, P. J. K. \& Metcalfe, N. B. 1992: Variation in the nomadic tendency of a wintering finch Carduelis spinus and its relationship with body condition. - Ornis Scandinavica 23: 63-72.

Simons, L. S. \& Simons, L. H. 1990: Experimental studies of nest-destroying behavior by cactus wrens. - Condor 92: 855-860.

StatSoft Inc. 2001: STATISTICA Data Analysis Software System, ver. 6. - Tulsa, Oklahoma, USA, www.statsoft. com.

van Schaik, C. P. \& Janson, C. H. 2000: Infanticide by males and its implications. - Cambridge University Press, Cambridge.

Veiga, J. P. 1990: Infanticide by male and female house sparrows. - Animal Behaviour 39: 496-502.

Veiga, J. P. 2004: Replacement female house sparrows regularly commit infanticide: gaining time or signaling status? - Behavioral Ecology 15: 219-222.

Weisheit, A. S. \& Creighton, P. D. 1989: Interference by house sparrows in nesting activities of barn swallows. Journal of Field Ornithology 60: 323-328.

Yong, W. \& Moore, F. R. 1997: Spring stopover of intercontinental migratory trushes along the northern coast of the Gulf of Mexico. - Auk 114: 263-278. 